\title{
Evaluation of Dermal Irritation and Skin Sensitization by Curaderm
}

\author{
T. Chase, K. E. Cham, B. E. Cham \\ Australasian Medical Research, Port Vila, Republic of Vanuatu \\ Email: bill.cham@gmail.com
}

How to cite this paper: Chase, T., Cham, K.E. and Cham, B.E. (2020) Evaluation of Dermal Irritation and Skin Sensitization by Curaderm. International Journal of Clinical Medicine, 11, 548-558.

https://doi.org/10.4236/ijcm.2020.119047

Received: September 1, 2020

Accepted: September 19, 2020

Published: September 22, 2020

Copyright $\odot 2020$ by author(s) and Scientific Research Publishing Inc. This work is licensed under the Creative Commons Attribution International License (CC BY 4.0).

http://creativecommons.org/licenses/by/4.0/

\section{(c) (i) Open Access}

\begin{abstract}
Purpose: To establish whether Curaderm, a topical pharmacotherapy for skin cancer, irritates or sensitizes normal skin. Methods: The dermal irritation and skin sensitization toxicity of Curaderm were investigated in rabbits and guinea pigs in compliance with the Organization for Economic Cooperation and Development guideline. To assess dermal irritation, rabbits were dermally exposed to Curaderm for varying periods of time. To assess hypersensitivity, the guinea-pig maximisation test was applied. Results: Curaderm was only negligibly irritating using the criteria of erythema and oedema. Curaderm did not produce any sensitization toxicity of the skin. Conclusion: These studies confirm the non-toxic observations on normal skin experienced in the clinical setting when treating skin cancer and reinforce the specificity of Curaderm towards cancer cells.
\end{abstract}

\section{Keywords}

Curaderm, BEC, Solamargine, Skin Cancer, Dermal Irritation, Skin Sensitization, Psoriasis

\section{Introduction}

In 1987, it was reported that plant-derived glycoalkaloids-BEC [1] induced anticancer effects in cell culture [2] [3] [4], animals [5], and humans [6] [7].

$\mathrm{BEC}$, the initials of the inventor of this technology, is composed mainly of solamargine and solasonine [1]. The anticancer effect of solamargine is 9 times more potent than solasonine [8].

Since then, a plethora of further investigations has taken place resulting in the placement of BEC as a very promising antineoplastic agent with vast potential to serve as a targeted anticancer agent [9]-[23].

Anticancer efficacy studies have determined that BEC specifically targets a 
wide variety of cancer cells [24], but has no deleterious effects on normal cells [25]. Toxicity studies of BEC have been well documented [8].

Consequently, cream formulations for the treatment of skin cancer in humans were investigated. Ultimately, an effective topical cream formulation, Curaderm, was devised [6] [25]-[30]. Very low concentrations of BEC are present in Curaderm, corresponding to similar concentrations of BEC used in cell culture and animal anticancer studies.

Moreover, the amount of BEC in one tube $(20 \mathrm{~mL})$ of Curaderm is $1 \mathrm{mg}$ BEC and is equivalent to the content of BEC in 10 grams of eggplant fruit [25] [31].

In addition, toxicological studies have shown that at this concentration of BEC, it is completely harmless [5].

However, in order for Curaderm to be effective, at very low concentrations of BEC, for treating skin cancers, keratolytic agents were necessary to enhance the bioavailability of BEC with the skin cancer cells [18] [32].

The concentrations of the keratolytic agents in Curaderm are within the concentration range that is found in many skin care products. Notwithstanding the apparent safety profile of the separate ingredients in Curaderm, it was considered appropriate to conduct biocompatibility studies with Curaderm that entailed all ingredients in Curaderm representing the end product that is used by patients. The reason for this approach is to ensure that the individual components in Curaderm do not interact with one another to exert properties of unknown and/or unwanted sequelae. For example, in a positive manner, it was recently reported that BEC shows a synergistic anti-cancer effect with cisplatin [24].

Similarly, BEC when added to an anti-psoriasis cream formulation vastly improves its therapeutic effect [33].

The significance of having available an effective, safe and simple treatment for skin cancer and psoriasis is of paramount importance. For example,

- The incidence of skin cancer is higher than all other cancers combined.

- The incidence of skin cancer is rapidly increasing worldwide.

- Skin cancers are major causes of morbidity and mortality.

- The cost of skin cancer in the USA alone is US\$1.5 billion yearly and rapidly increasing. This is of concern to the Health Care System and public [34].

Similarly, psoriasis is a chronic autoimmune disease that affects $1 \%$ to $3 \%$ of the general population and involves an estimated 4.5 to 7.5 million Americans. The effects of the disease on the quality of life or physical and emotional well-being are well known. The heavy economic burden of psoriasis has been estimated to exceed US\$3 billion to the Health-Care Industry annually [35].

The strengths and limitations of currently used treatments for skin cancer and psoriasis have been documented. There is no doubt, a great need for simple, safe and effective treatments for these diseases are required. The safety studies reported in this communication contribute partly to the establishment of such a requirement. 


\section{Materials and Methods}

The biocompatibility procedures were followed by the recommended ISO 1099310:2010-current edition procedure. The animal welfare requirements were according to ISO 10993-2:2006-Part 2: Animal welfare requirements.

Curaderm cream in a $20 \mathrm{~mL}$ tube. Batch number 014672 was obtained from Curaderm Global Limited. Curaderm was composed of $5 \mathrm{mg} \%$ BEC, 10\% salicylic acid and 5\% urea in a stabilized cetomacrogol cream base.

\section{Rabbits}

Three male White New Zealand rabbits weighing 3675 - 3690 grams were used.

Before commencement of this study, the rabbits were kept in quarantine and were acclimatized for one week. They were observed daily during this period. At the end of the quarantine week, the rabbits were carefully examined to evaluate their suitability for the study. Animals were then randomly selected from the suitable assessed group.

Each rabbit was housed in NORYL cages with the dimensions of $70 \mathrm{~cm} \times 70$ $\mathrm{cm} \times 47 \mathrm{~cm}$ height, the cages were identified by a label. The animal facility was maintained as recommended by ISO 10993-2:2006-Part 2: Animal welfare requirements, and a $12 \mathrm{~h}$ light/dark cycle with fluorescent lamps throughout the experiments. The room temperature and humidity were regulated by an air conditioning unit and were continuously monitored.

The cages and the housing room were cleaned before accommodation of the rabbits and subsequent cleaning and disinfecting were periodically performed. The rabbits were fed with a standard pellet complete diet (LAP KLIBA). Filtered tap water was supplied ad libitum. The animals were identified by number tagging through the edge of the right ear.

\section{Treatment region}

The right caudal region and left cranial region of each animal were treated with $0.5 \mathrm{~mL}$ Curaderm cream per each region. As control, an established nonirritant gauze $(25 \mathrm{~mm} \times 25 \mathrm{~mm})$ humified with physiological solution was applied to the right cranial region and the left caudal region.

\section{Skin preparation}

Approximately 24 hours before commencement of the test, the fur was removed from an area of approximately $240 \mathrm{~cm}^{2}$ wide by clipping and shaving the dorsal and flank zones of the animals. An area of the back of approximately 6 $\mathrm{cm}^{2}$ was used for the application of $0.5 \mathrm{~mL}$ test samples directly to the skin and covered with a non-occlusive dressing, thus protecting the trunk of each rabbit. The patches were removed 4 hours after application.

General conditions of the animals were verified daily. Reactions were evaluated following the removal of the patches and were evaluated again at 24, 48 and 72 hours after exposure. Skin irritation was scored and recorded to the scores reported in Table 1.

Acute dermal irritation 
Table 1. Scoring of skin irritation.

\section{GRADING VALUES}

\begin{tabular}{l}
\hline \begin{tabular}{l}
\hline Erythema and eschar formation \\
No erythema
\end{tabular} \\
$\begin{array}{l}\text { Very slight erythema (barely perceptible) } \\
\text { Well-defined erythema }\end{array}$ \\
$\begin{array}{l}\text { Moderate erythema } \\
\text { Severe erythema (beet redness with slight eschar formation; injuries in depth) }\end{array}$ \\
$\begin{array}{l}\text { Oedema formation } \\
\text { No oedema }\end{array}$ \\
$\begin{array}{l}\text { Very slight oedema (barely perceptible) } \\
\text { Slight oedema (edges of area well defined by definite raising) }\end{array}$ \\
$\begin{array}{l}\text { Moderate oedema (raised approximately } 1 \text { mm) } \\
\text { Severe oedema (raised more than } 1 \text { mm and extending beyond the area of exposure) }\end{array}$ \\
\hline
\end{tabular}

The acute dermal irritation study was performed in accordance with the ISO 10993-10:2010-current edition guidelines. Dermal responses were determined in accordance with OECD guidelines. Erythema and Oedema were scored on a scale of $0-4$, with 0 showing no effect and 4 representing severe symptoms reported in Table 1.

\section{Interpretation of the observations}

For the acute exposure, the Primary Irritation Index (PII) is determined as follows.

For each animal, the PII scores of erythema and Oedema for Curaderm were added at each specified time point. These values were then divided by the total number of observations (two tests/observation sites) with the three time points.

The PII of the controls were similarly calculated and these values were then deducted from the scores of the Curaderm treatment.

This resulted in the PII score of Curaderm at the observation times 24, 48 and 72 hours. The scores for each animal were added and then divided by the total number of animals yielding the value of PII for Curaderm.

Table 2 shows the criteria used for the evaluation of Curaderm's Primary Irritation Index.

\section{Guinea Pigs}

Eighteen guinea pigs weighing 300 - 500 grams were used in the Delayed Hypersensitivity Test, also known as the Guinea Pig Maximisation Test (GPMT).

A group of 10 animals was treated with Curaderm, a group of 5 animals served as controls and another group of 3 animals were used for preliminary testing. The GPMT consisted of a preliminary test, an induction phase and a challenge phase.

The housing and conditions of keeping the animals were as described for the 
Table 2. Characterization of the primary irritation index.

\begin{tabular}{cc}
\hline Response category & Mean score \\
\hline Negligible & 0 to 0.5 \\
Slight & $>0.5$ to 2 \\
Moderate & $>2$ to 5 \\
Severe & $>5$ to 8 \\
\hline
\end{tabular}

rabbits, with the exceptions that all animals were non-pregnant females and they were caged in groups of five in NORYL cage with the dimensions of $74.3 \mathrm{~cm} \times$ $54.3 \mathrm{~cm} \times 25 \mathrm{~cm}$. The animals were fed with a standard complete diet (KLIBA).

The preliminary test was used to determine the appropriate concentration of Curaderm cream for use in the sensitization test. Neat (100\%), 90\%, $80 \%$, and $70 \%$ of the Curaderm formulation was tested.

When appropriate, Curaderm was diluted with sterile physiological Sodium Chloride solution. No erythema was observed with the diluted or neat Curaderm.

Consequently, undiluted, neat Curaderm was used for the topical application for the induction and challenge phases.

For the suitability of the injection at the induction phase, Curaderm was diluted 1:1 $(\mathrm{mL} / \mathrm{mL})$ with intradermal stabilized emulsion injections containing Freund's complete adjuvant and sodium chloride.

The skin sensitization test was conducted according to the OECD guideline.

One day before the first induction, fifteen healthy guinea pigs were assigned to two groups: a placebo group $(n=5)$, and a transdermal patch Curadermtreated group $(\mathrm{n}=10)$. Approximately $50 \mathrm{~cm}^{2}$ wide area on the back of each guinea pig was clipped for experimental use. Transdermal patch was applied to the shaved area of each animal at the induction phase.

On day zero, $0.1 \mathrm{~mL}$ was injected intradermally in the interscapular region of each animal on each side of the midline. Six days after the induction, topical application occurred by gentle massage. Seven days after the intradermal injections, $0.5 \mathrm{~mL}$ of the test sample or placebo was applied to the corresponding animal and held in place with an occlusive patch. The dressing was left in place for 48 hours.

The challenge phase occurred 14 days after the topical induction phase. An occlusive patch with $0.5 \mathrm{~mL}$ of the Curaderm sample was applied to the right flank of all 15 guinea pigs, whereas sodium chloride solution was applied to the left flank. The dressing was left in place for 24 hours. 24 and 48 hours after removal of the patches all treated and control animals were evaluated for possible skin reactions. The intensity of erythema and/or oedema was evaluated according to the scale in Table 3.

\section{Positive controls}

Reliability of the experimental procedures was validated every six months using positive controls with Mercaptobenzothiazole according to OECD 406 and ISO 10993-10. 
Table 3. Grading of the intensity of erythema and/or oedema.

\begin{tabular}{cc}
\hline Patch test reaction & Grading scale \\
\hline No visible change & 0 \\
Discrete or patchy erythema & 1 \\
Moderate and confluent erythema & 2 \\
Intense erythema and swelling & 3 \\
\hline
\end{tabular}

\section{Results}

\section{Skin irritation test in rabbits}

A slight erythema was detected in all treated sites of three animals at $60 \mathrm{mi}-$ nutes and 24 hours after removal of the dressing. A slight erythema was observed in all treated sites of one animal (number 1200), 48 hours after removal of the dressing. No changes were detected at all sites of all three animals 72 hours after removal of the dressing. Similarly, no changes were detected at all control sites throughout the experimental period (Table 4).

With this assessment, it was concluded that the Primary Skin Irritation index (Treated minus Control) is 0.44 and is considered NEGLIGIBLY IRRITANT to the skin.

\section{Delayed hypersensitivity test in guinea pigs}

No sensitization was noted among the guinea pigs that were challenged with Curaderm patch or with the placebo patch. Similarly, no erythema or oedema was observed after the challenge with Curaderm or placebo. None of the ten Curaderm treated rabbits produced skin reactions at 24 hours and 48 hours after the patches were removed. This was also the case with the five control animals.

\section{Positive controls}

The sensitivity and reliability of the experimental procedure are assessed every 6 months following the conditions of OECD 406 and ISO 10993-10 by the centre carrying out this study. During the current study period a reliability study was performed utilizing 2\% Mercaptobenzothiazole in cottonseed for the intradermic injection at the induction phase, $45 \%$ Mercaptobenzothiazole in cottonseed for the topical application of the induction phase and 30\% Mercaptobenzothiazole in cottonseed oil for the challenge phase. Fifty percent of the treated animals showed a positive skin reaction, whereas, the control placebo animals showed no skin reactions.

During the experimental period, the general wellbeing of all animals was monitored and was not affected.

\section{Discussion}

It is usual practice to evaluate "new" substances that are to be introduced into the marketplace for possible risks that may affect the end user.

The toxicity of BEC has been evaluated with cell culture studies, animal studies and human studies resulting in high safety outcomes at therapeutic concentrations. 
Table 4. Evaluation of skin irritation of Curaderm and placebo controls over 72 hours observation in rabbits.

\begin{tabular}{|c|c|c|c|c|c|c|c|c|c|c|c|c|c|}
\hline \multirow{5}{*}{$\begin{array}{c}\text { Time After Removal } \\
\text { of Patch }\end{array}$} & \multirow{5}{*}{ REACTION } & \multicolumn{11}{|c|}{ RABBIT N. } & \\
\hline & & \multicolumn{4}{|c|}{1200} & \multicolumn{4}{|c|}{1206} & \multicolumn{4}{|c|}{1213} \\
\hline & & \multicolumn{2}{|c|}{ TREATED } & \multicolumn{2}{|c|}{ CONTROL } & \multicolumn{2}{|c|}{ TREATED } & \multicolumn{2}{|c|}{ CONTROL } & \multicolumn{2}{|c|}{ TREATED } & \multicolumn{2}{|c|}{ CONTROL } \\
\hline & & $\mathrm{CA}$ & CR & $\mathrm{CA}$ & $\mathrm{CR}$ & $\mathrm{CA}$ & CR & $\mathrm{CA}$ & CR & $\mathrm{CA}$ & CR & $\mathrm{CA}$ & CR \\
\hline & & $\mathrm{dx}$ & $\mathbf{s x}$ & $\mathbf{s x}$ & $\mathrm{d} \mathbf{x}$ & $\mathrm{dx}$ & $\mathbf{s x}$ & $\mathbf{s x}$ & $\mathrm{dx}$ & $\mathrm{dx}$ & $s x$ & $s \mathbf{x}$ & $d x$ \\
\hline \multirow[t]{2}{*}{60 minutes } & Erythema & 1 & 1 & 0 & 0 & 1 & 1 & 0 & 0 & 1 & 1 & 0 & 0 \\
\hline & Oedema & 0 & 0 & 0 & 0 & 0 & 0 & 0 & 0 & 0 & 0 & 0 & 0 \\
\hline \multirow[t]{2}{*}{24 hours } & Erythema & 1 & 1 & 0 & 0 & 1 & 1 & 0 & 0 & 1 & 1 & 0 & 0 \\
\hline & Oedema & 0 & 0 & 0 & 0 & 0 & 0 & 0 & 0 & 0 & 0 & 0 & 0 \\
\hline \multirow[t]{2}{*}{48 hours } & Erythema & 1 & 1 & 0 & 0 & 0 & 0 & 0 & 0 & 0 & 0 & 0 & 0 \\
\hline & Oedema & 0 & 0 & 0 & 0 & 0 & 0 & 0 & 0 & 0 & 0 & 0 & 0 \\
\hline \multirow[t]{2}{*}{72 hours } & Erythema & 0 & 0 & 0 & 0 & 0 & 0 & 0 & 0 & 0 & 0 & 0 & 0 \\
\hline & Oedema & 0 & 0 & 0 & 0 & 0 & 0 & 0 & 0 & 0 & 0 & 0 & 0 \\
\hline
\end{tabular}

$\mathrm{CA}=$ Caudal, $\mathrm{CR}=$ Cranial, $\mathrm{dx}=$ Right, $\mathrm{sx}=$ Left.

The approval of a drug to enter the market place is achieved after passing Phases I, II and III of clinical trials. The success of a drug depends on the outcome of Phase IV clinical trial observations showing that the new drug has been proven to be safe for its use by the general public. An example has occurred recently whereby a drug for the treatment of keratosis had to be withdrawn from the marketplace because of unacceptable side effects observed during Phase IV observations. In order to minimize such occurrences, tests such as irritation tests and sensitivity tests of the new drug are carried out. Although help-full, these tests do not guarantee full safety.

The new active ingredient of a formulation may be biocompatible with the skin, but it is the full formulation that the public will use that has to be safe.

In the current study, irritation of Curaderm to the skin has been investigated by assessing its erythema and oedema effects on the skin. Erythema is redness of the skin caused by hyperaemia of superficial capillaries. Oedema is the swelling caused by fluid in the body's tissue.

Under the conditions studied, Curaderm was negligibly irritant to the skin. This is not surprising, since $10 \%$ salicylic acid and 5\% urea were added to the formulation to obtain improved bioavailability of BEC with the skin cancer cells [32], without harming normal skin. The limitation of the current investigation is that not all parameters that may indicate irritation or sensitivity were studied.

It is interesting that in the clinical setting when treating skin cancers with $\mathrm{Cu}$ raderm, no adverse reactions are observed when Curaderm is applied to normal skin surrounding the skin cancer lesion. However, the reported reactions of transient erythema, pruritis, swelling, postulation and ulceration of Curaderm therapy with actual skin cancers appear to be related to BEC in Curaderm specifically interacting and disposing of the cancer cells. 
These results also explain why the observed side effects are minimal when Curaderm is used by the public to treat skin cancers [36].

The results in this communication show that Curaderm is negligibly irritating to the skin of rabbits and that there is no sensitization of Curaderm to guinea pigs, supporting the clinical observations in humans who are treated with Curaderm for skin cancer.

\section{Conclusions}

Treatment of skin cancers with Curaderm has reportedly resulted in impressive efficacious and cosmetic outcomes. To have a treatment available that specifically seeks out and destroys cancer cells by stimulating apoptosis and yet does not affect normal cells is a rare phenomenon. BEC in Curaderm is a targeted therapy for treating skin cancers. This is unlike other skin cancer treatments, including surgery.

The results in this communication enforce the clinical observations that pharmacotherapy of skin cancers with Curaderm results in the removal of cancer cells without affecting normal cells resulting in the impressive cosmetic outcomes.

\section{Acknowledgements}

These studies were commissioned to Eurochem Ricerche SRL-Italy by Curaderm Global Limited who partly interpreted the article.

\section{Conflicts of Interest}

The authors declare no conflicts of interest regarding the publication of this paper.

\section{References}

[1] Cham, B.E. and Wilson, L. (1987) HPLC of Glycoalkaloids from Solanum sodomaeum. Planta Medica, 1, 59-62. https://doi.org/10.1055/s-2006-962621

[2] Cham, B.E. (1988) Monograph BEC. Drugs of the Future, 13, 714-716. https://doi.org/10.1358/dof.1988.013.08.63026

[3] Daunter, B. and Cham, B.E. (1990) Solasodine Glycosides. In Vitro Preferential Cytotoxicity for Human Cancer Cells. Cancer Letters, 55, 209-220. https://doi.org/10.1016/0304-3835(90)90121-D

[4] Cham, B.E. and Daunter, B. (1990) Solasodine Glycosides. Selective Cytotoxicity for Cancer Cells and Inhibition of Cytotoxicity by Rhamnose in Mice with Sarcoma 180. Cancer Letters, 55, 221-225. https://doi.org/10.1016/0304-3835(90)90122-E

[5] Cham, B.E. (2017) Solasodine, Solamargine and Mixtures of Solasodine Rhamnosides: Pathway to Expansive Clinical Anticancer Therapies. International Journal of Clinical Medicine, 8, 692-713. https://doi.org/10.4236/ijcm.2017.812064

[6] Cham, B.E. and Daunter, B. (1990) Topical Treatment of Pre-Malignant and Malignant Skin Cancers with Curaderm. Drugs of Today, 26, 55-58.

[7] Cham, B.E. and Meares, H.M. (1987) Glycoalkaloids from Solanum sodomaeum L. 
Are Effective in the Treatment of Skin Cancers in Man. Cancer Letters, 36, 111-118. https://doi.org/10.1016/0304-3835(87)90081-4

[8] Cham, A., Cham, K., Chase, T. and Cham, B. (2015) A Standardized Plant Extract Containing a Target Compound Is Acceptable as a Potent Therapeutic Entity: Relevance to BEC and Solamargine, a Topical Clinical Formulation Curaderm ${ }^{\mathrm{BEC} 5}$. Journal of Cancer Treatment and Research, 3, 22-27. https://doi.org/10.11648/j.jctr.20150302.12

[9] Wang, Y., Gao, J., Gu, G., Li, G., Cui, C., Sun, B., et al. (2011) In Situ RBL Receptor Visualisation and Its Mediated Anticancer Activity for Solasodine Rhamnosides. ChemBioChem, 12, 2418-2420. https://doi.org/10.1002/cbic.201100551

[10] An, W., Lai, H., Zhang, Y., Liu, M., Lin, X. and Cao, S. (2019) Apoptotic Pathway as the Therapeutic Target for Anticancer Traditional Chinese Medicines. Frontiers in Pharmacology, 10, 758. https://doi.org/10.3389/fphar.2019.00758

[11] Li, X., Zhao, Y., Wu, W.K., Liu, S., Cui, M. and Lou, H. (2011) Solamargine Induces Apoptosis with p53 Transcription-Dependent and Transcription-Independent Pathways in Human Osteosarcoma U2OS Cells. Life Sciences, 88, 314-321. https://doi.org/10.1016/j.lfs.2010.12.006

[12] Al Sinani, S.S., Eltayeb, E.A., Coomber, B.L. and Adham, S.A. (2016) Solamargine Triggers Cellular Necrosis Selectively in Different Types of Human Melanoma Cancer Cells through Extrinsic Lysosomal Mitochondrial Death Pathways. Cancer Cell International, 16, 287-294. https://doi.org/10.1186/s12935-016-0287-4

[13] Zang, X., Yan, Z., Xu, T., An, Z., Chen, W., Wang, X., Huang, M. and Zhu, F. (2018) SM Derived from Solanum nigrum Induces Apoptosis of Human Cholangio Carcinoma QBC939 Cells. Oncology Letters, 15, 6329-6335. https://doi.org/10.3892/ol.2018.8171

[14] Al Sinani, S.S.S. and Eltayeb, E.A. (2017) The Steroidal Glycoalkaloids Solamargine and Solasonine in Solanum Plants. South African Journal of Botany, 112, 253-269. https://doi.org/10.1016/j.sajb.2017.06.002

[15] Kalalinia, F. and Korimi-Sani, I. (2017) Anticancer Properties of Solamargine: A Systematic Review. Phytotherapy Research, 31, 858-870. https://doi.org/10.1002/ptr.5809

[16] Fu, R., Wang, X., Hu, Y., Du, H., Deng, B., Ao, S., Zhang, L., Sun, Z., Zhang, L., Lv, G. and Ji, J. (2019) Solamargine Inhibits Gastric Cancer Progression by Regulating the Expression of nc NEAT 1-2 via the MAPK Signaling Pathway. International Journal of Oncology, 54, 1545-1554. https://doi.org/10.3892/ijo.2019.4744

[17] Sani, I.K., Marashi, S.H. and Kalalinia, F. (2015) Solamargine Inhibits Migration and Invasion of Human Hepatocellular Carcinoma Cells through Down-Regulation of Matrix Metalloproteinases 2 and 9 Expression and Activity. Toxicology in Vitro, 29, 893-900. https://doi.org/10.1016/j.tiv.2015.03.012

[18] Cham, B.E. (2013) Inspired by Nature, Proven by Science. The New Generation Cancer Treatment That Causes Cancer Cells to Commit Suicide. Colorite Graphics Book, $264 \mathrm{p}$.

[19] Wu, J., Tang, X., Ma, C., Shi, Y., Wu, W. and Hann, S. (2020) The Regulation and Interaction of Colon Cancer-Associated Transcript-1 and miR7-5p Contribute to the Inhibition of SP1 Expression by Solamargine in Human Nasopharyngeal Carcinoma Cells. Phytotherapy Research, 34, 201-213. https://doi.org/10.1002/ptr.6555

[20] Shiu, L.Y., Chang, L.C., Liang, C.H., Huang, Y.S., Sheu, H.M. and Kuo, K.W. (2007) Solamargine Induces Apoptosis and Sensitizes Breast Cancer Cells to Cisplatin. Food and Chemical Toxicology, 45, 2155-2164. 
https://doi.org/10.1016/j.fct.2007.05.009

[21] Sun, L., Zhao, Y., Li, X., Yuan, H., Cheng, A. and Lou, H. (2010) A Lysosomal-Mitochondrial Death Pathway Is Induced by Solamargine in Human K562 Leukemia Cells. Toxicology in Vitro, 24, 1504-1511. https://doi.org/10.1016/j.tiv.2010.07.013

[22] Millward, M., Powell, A., Tyson, S., Daly, P., Ferguson, R. and Carter, S. (2005) Phase 1 Trial of Coramsine (SBP002) in Patient with Advanced Solid Tumors. Journal of Clinical Oncology, 23, 3105. https://doi.org/10.1200/jco.2005.23.16_suppl.3105

[23] Munari, C.C., de Oliveira, P.F., Campos, J.C.L., Martins, S.P.L., Da Costa, J.C., Bastos, J.K. and Tavares, D.C. (2014) Antiproliferative Activity of Solanum lycocarpum Alkaloidal Extract and Their Constituents, Solamargine and Solasonine, in Tumor Cell Lines. Journal of Natural Medicines, 68, 236-241. https://doi.org/10.1007/s11418-013-0757-0

[24] Cham, B.E. (2020) Combination Treatment with BEC and Cisplatin Synergistically Augments Anticancer Activity and Results in Increased Absolute Survival. Journal of Cancer Therapy, 11, 470-482. https://doi.org/10.4236/jct.2020.118040

[25] Cham, B.E. (2013) Drug Therapy: Solamargine and Other Solasodine Rhamnosyl Glycosides as Anticancer Agents. Modern Chemotherapy, 2, 33-49. https://doi.org/10.4236/mc.2013.22005

[26] Cham, B.E., Daunter, B. and Evans, R. (1991) Topical Treatment of Malignant and Premalignant Skin Cancers by Very Low Concentrations of a Standard Mixture of Solasodine Glycosides. Cancer Letters, 59, 183-192. https://doi.org/10.1016/0304-3835(91)90140-D

[27] Chase, T.R. (2011) Curaderm ${ }^{\mathrm{BEC} 5}$ for Skin Cancers, Is It? An Overview. Journal of Cancer Therapy, 2, 728-745. https://doi.org/10.4236/jct.2011.25099

[28] Batsev, A.F., Dobrokhotova, V.Z. and Cham, B.E. (2016) Topical Cream Curaderm${ }^{\mathrm{BEC} 5}$ Treats a Recalcitrant Basal Cell Carcinoma. Clinical Medical Reviews and Case Reports, 3, 098. https://doi.org/10.23937/2378-3656/1410098

[29] Goldberg, L.H., Landau, J.M., Moody, M.N. and Vergilis-Kalner, I.J. (2011) Treatment of Bowen's Disease on the Penis with Low Concentrations of a Standard Mixture of Solasodine Glycosides and Liquid Nitrogen. Dermatologic Surgery, 37, 858-861. https://doi.org/10.1111/j.1524-4725.2011.02014.x

[30] Punjabi, S., Cook, L.J., Kersey, P., Marks, R. and Cerio, R. (2008) Solasodine Glycoalkaloids: A Novel Topical Therapy for Basal Cell Carcinoma. A Double Blind, Randomized, Placebo-Controlled, Parallel Group, Multicentre Study. International Journal of Dermatology, 47, 78-82. https://doi.org/10.1111/j.1365-4632.2007.03363.x

[31] Jones, P.G. and Fredrick, G.R. (1981) The Glycoalkaloid Content of Some Edible Solanaceous Fruits and Potato Products. Journal of the Science of Food and Agriculture, 32, 419-421. https://doi.org/10.1002/jsfa.2740320418

[32] Cham, B.E., Chase, T.R. and Cham, K.E. (2020) Glycoalkaloid Combinations and Various Uses Thereof. Patent PCT/AU2017/050188.

[33] Cham, B.E. (2019) Solasodine Glycosides from the Eggplant in a Topical Cream Psorend ${ }^{\mathrm{BEC}}$ Are Effective against Psoriasis. International Journal of Clinical Medicine, 10, 174-182. https://doi.org/10.4236/ijcm.2019.103017

[34] Cham, B.E. (2020) Curaderm, the Undaunted New Kid on the Block for Treating Skin Cancer.

[35] Beyer, V. and Wolverton, S.E. (2010) Recent Trends in Systemic Psoriasis Treat- 
ment Costs. Archives of Dermatology, 46, 46-54.

https://doi.org/10.1001/archdermatol.2009.319

[36] Cham, B.E. (2015) Curaderm ${ }^{\mathrm{BEC} 5}$, Natural Non-Invasive Medication for Skin Cancer. Biopsy and 5 Year Cancer-Free Criteria. 2nd Edition, Curaderm Global Ltd., Port Vila. 